\title{
Amounts and Types of Epicuticular Leaf Waxes among Onion Accessions Selected for Reduced Damage by Onion Thrips
}

\author{
Eduardo D. Munaiz \\ Department of Horticulture, 1575 Linden Drive, University of Wisconsin, Madison, WI 53706
}

Russell L. Groves
Department of Entomology, 1630 Linden Drive, University of Wisconsin, Madison, WI 53706

Michael J. Havey

USDA-ARS and Department of Horticulture, 1575 Linden Drive, University of Wisconsin, Madison, WI 53706

\begin{abstract}
AdDitional INDEX words. alkanes, fatty alcohols, glossy foliage, insect resistance, ketones
Abstract. Onion thrips (Thrips tabaci) is the main insect pest of onion (Allium cepa), and feeding damage routinely causes serious yield losses. Lower amounts of epicuticular waxes on onion leaves have been associated with fewer onion thrips and less feeding damage, and research is needed to assess the relationships between amounts and composition of epicuticular waxes and feeding damage by onion thrips. This study used gas chromatography mass spectroscopy to determine amounts and types of epicuticular waxes on the foliage of onion accessions that had been field-selected for lower damage from onion thrips. Hentriacontanone-16 (H16), octaconasol-1, and triacontanol-1 were the most prevalent waxes on the foliage of these selections. Amounts of H16 were significantly lower on selections visually classified as having glossy or semiglossy foliage. Semiglossy selections were identified with similar amounts of total epicuticular wax as waxy phenotypes, due primarily to lower amounts of $\mathrm{H16}$ and higher amounts of other waxes. These semiglossy selections suffered significantly less feeding damage from onion thrips in a field evaluation, supporting the identification of unique wax profiles toward the development of thrips-resistant onion.
\end{abstract}

Feeding by onion thrips routinely causes severe damage to onion foliage and significantly reduces both bulb and seed yields (Diaz-Montano et al., 2010; Elmore, 1949; Fournier et al., 1995; Jones et al., 1934; Kendall and Capinera, 1987; Parrella and Lewis, 1997). Insecticides are commonly used to control onion thrips; however, populations have evolved resistance to pyrethroid and organophosphate insecticides (Herron et al., 2008; Shelton et al., 2003), reducing control options for growers. Management of onion thrips remains challenging due to the number of generations per season and large host range of the insect, as well as difficulty of sprays reaching between leaves.

Onion germplasm has been identified that suffers less damage by onion thrips. In field evaluations of plant introductions (PIs) from different regions of the world, Jones et al. (1934) reported that one accession of 'White Persian' onion had fewer onion thrips per plant. This accession was morphologically unique with light-green foliage, and subsequent research has documented that onion cultivars with lighter-green foliage support lower numbers of onion thrips and suffer less feeding damage (Boateng et al., 2014; Cramer et al., 2014; Damon et al.,

Received for publication 14 June 2019. Accepted for publication 8 Oct. 2019. Published online 14 November 2019.

We gratefully acknowledge the support of USDA-NIFA grants 2008-5118004875 from the Specialty Crops Research Initiative and 2016-6013-24590 from the Organic Research and Extension Initiative.

Product names are necessary to report factually on available data; however, the U.S. Department of Agriculture (USDA) neither guarantees nor warrants the standard of the product, and the use of the name by USDA implies no approval of the product to the exclusion of others that may also be suitable.

M.H. is the corresponding author. E-mail: michael.havey@usda.gov.

This is an open access article distributed under the CC BY-NC-ND license (https://creativecommons.org/licenses/by-nc-nd/4.0/).
2014; Diaz-Montano et al., 2010; Jones et al., 1935). Light-green leaf color in onion has been associated with chemical composition of epicuticular waxes on foliage (Damon et al., 2014; Jones et al., 1944; Maughan and MacLeod, 1936; Molenaar, 1984). The epicuticular waxes in Allium are a mixture of long chain fatty acids (C20 to $\mathrm{C} 30$ ) and their derivatives (Rhee et al., 1998). H16 is the main epicuticular wax on leek (Allium ampelorasum) foliage and represents more than $15 \%$ of the total lipids. Damon et al. (2014) used gas chromatographymass spectrometry (GCMS) to identify amounts and compositions of epicuticular waxes on the foliage of four onion inbreds with glossy (low wax), semiglossy (intermediate wax), and waxy (copious wax) phenotypes; these authors observed that lower thrip numbers and feeding damage were observed on onions with lower amounts of H16 and total epicuticular wax compared with susceptible phenotypes. In contrast, Njau et al. (2017) reported that total amounts of epicuticular wax were not correlated with onion thrips damage on onion in Tanzania. However Njau et al. (2017) extracted total epicuticular waxes from onion foliage and neither identified nor quantified these waxes. In our study, we used GCMS to measure the types and amounts of epicuticular waxes on foliage of diverse onion accessions that had been selected for reduced damage by onion thrips. We also assessed feeding damage by onion thrips to determine if specific wax profiles, as opposed to total amount of waxes, were associated with reduced damage by onion thrips.

\section{Materials and Methods}

Plant material. Fourteen onion accessions (Table 1) were assessed for epicuticular wax profiles and damage by onion 
Table 1. Origins and visually assessed foliage phenotypes of onion accessions evaluated for epicuticular waxes and feeding damage by onion thrips.

\begin{tabular}{|c|c|c|c|}
\hline Accession $^{z}$ & Origin & Visual phenotype $^{\mathrm{y}}$ & $\begin{array}{c}\text { Avg score }[\text { mean } \pm \mathrm{SD} \\
(1-5 \text { scale })]^{\mathrm{y}} \\
\end{array}$ \\
\hline B9885 & USDA & GL & $1.0 \pm 0.0$ \\
\hline $264320-1$ & Spain & SG & $1.3 \pm 0.6$ \\
\hline B5351 & USDA & $\mathrm{SG}$ & $1.7 \pm 1.2$ \\
\hline $264320-2$ & Spain & SG & $1.7 \pm 1.2$ \\
\hline 546101 & Spain & SG & $3.0 \pm 0.0$ \\
\hline 546201 & USA & SG & $3.0 \pm 0.0$ \\
\hline 546192 & USA & $\mathrm{SG}$ & $3.0 \pm 0.0$ \\
\hline 288903 & Hungary & WX & $5.0 \pm 0.0$ \\
\hline 264648 & Germany & WX & $5.0 \pm 0.0$ \\
\hline 546096 & USA & WX & $5.0 \pm 0.0$ \\
\hline 546106 & USA & WX & $5.0 \pm 0.0$ \\
\hline DH 2107 & Cornell Univ. & WX & $5.0 \pm 0.0$ \\
\hline $22452 \mathrm{AI}^{\mathrm{x}}$ & USDA & WX & $5.0 \pm 0.0$ \\
\hline 22452 AA $^{x}$ & USDA & WX & $5.0 \pm 0.0$ \\
\hline
\end{tabular}

${ }^{\bar{z}}$ Six-digit numbers are U.S. Department of Agriculture (USDA) plant introductions (PIs) selected in field trials for reduced damage by onion thrips (Boateng et al., 2014). Dashes indicate independent selections from PI 264320.

${ }^{\mathrm{y}}$ Visually classified phenotypes of glossy (GL), semiglossy (SG), or waxy (WX) foliage based on scores from 1 (glossy) to 5 (waxy) as shown in Fig. 1.

${ }^{\mathrm{x}}$ Waxy selections from the cross of DehyA $\times$ B5351 (Damon and Havey, 2014).
EPicuticular wax eVAluations. For evaluation of waxes using GCMS from plants in the CF16 and GH17 evaluations, two samples were taken from the middle section of the fourth leaf from each of six plants per accession. For Arl17A and Arl17B evaluations, two samples were taken from the middle section of the fourth leaf from each of two randomly chosen plants per accession from each of three blocks. Each sample was weighed and docosane (Sigma, St. Louis, MO) dissolved in high-performance liquid chromatography (HPLC) reagent grade chloroform (Thermo Fisher Scientific, Waltham, MA) was added as an internal standard at a rate of $100 \mu \mathrm{g} \cdot \mathrm{g}^{-1}$ fresh weight. Each leaf section was submerged into HPLC-grade chloroform and removed after $1 \mathrm{~min}$. Chloroform was evaporated in a fume hood for $\approx 5 \mathrm{~d}$. Dried extracts were dissolved in $500 \mu \mathrm{L}$ chloroform, followed by

thrips. Nine of these accessions were from the U.S. Department of Agriculture germplasm collection and had been visually selected for less damage by onion thrips in field evaluations in Colorado (Boateng et al., 2014). Five control accessions were included: B9885 (PI 546303) is an inbred with glossy foliage originating from 'White Persian'; B5351 is a inbred with semiglossy foliage selected from 'Colorado \#6'; DH2107 is a double haploid (DH) with waxy foliage; and 22452AI and 22452AA are waxy selections from the cross of DehyA $\times$ B5351 (Damon and Havey, 2014; Hyde et al., 2012; Molenaar, 1984).

In Jan. 2016, seeds of the 14 accessions were sown in a soilless medium (Metro-Mix; Sun Gro Horticulture, Agawam, MA) in 96-well trays in a greenhouse at the University of Wisconsin-Madison (UW) with growing conditions of 14-h days at 24 and $20{ }^{\circ} \mathrm{C}$ nights. Plants were watered daily and fertilized once per week with $20 \mathrm{~N}-8.8 \mathrm{P}-16.6 \mathrm{~K}$ water-soluble fertilizer (Peters Professional, Allentown, PA). At $72 \mathrm{~d}$ after seeding, individual plants were transferred to $10-\mathrm{cm}$-square pots with soilless mix in the greenhouse. Pots containing plants were moved outdoors at $120 \mathrm{~d}$ after seeding into coldframes at the UW Horticulture Research Farm (Arlington, WI), covered with a black net for $2 \mathrm{~d}$, and arranged in a completely randomized design (CRD) with six replications. At $170 \mathrm{~d}$ after seeding, leaves were sampled for GCMS as described below (evaluation CF16). In 2017, the 14 accessions were planted in the greenhouse as described for 2016, pots were arranged in a CRD with six replications, and leaves were sampled for analysis by GCMS at $71 \mathrm{~d}$ after planting (evaluation GH17).

In 2017, 13 accessions (without 546201 due to lack of seed) were grown in the greenhouse as described above and transplanted in early June into field plots in a randomized complete block design (RCBD) at two locations on the UW Horticulture Research Farm (evaluations Arl17A and Arl17B). Fifteen plants per accession were transplanted into three blocks with $5 \mathrm{~cm}$ between plants and $10-\mathrm{cm}$ separation between plots. Leaves were sampled for analysis by GCMS at $110 \mathrm{~d}$ after seeding. addition of $600 \mu \mathrm{L}$ acetronitrile (HPLC grade, Thermo Fisher Scientific) and derivatization with $210 \mu \mathrm{L} \mathrm{N}, \mathrm{O}$ bis(trimethylsilyl) tri-fluoroacetamide (BSTFA) (1\% trimethyl-chlorosilane, HPLC/GC grade; Sigma) for $30 \mathrm{~min}$ at $80{ }^{\circ} \mathrm{C}$. The GCMS instrument (QP2010; Shimadzu, Santa Clara CA) had a capillary column (SH-Rxi-5Sil MS, $30 \mathrm{~m}$ long; $0.30 \mathrm{~mm}$ i.d.; dim.f = $0.25 \mu \mathrm{m}$ ), and on-column injection at $250{ }^{\circ} \mathrm{C}$ and column oven temperature $150{ }^{\circ} \mathrm{C}$ constant for $10 \mathrm{~min}$, ramp $10{ }^{\circ} \mathrm{C} \cdot \mathrm{min}^{-1}$ to $300^{\circ} \mathrm{C}$, constant for $10 \mathrm{~min}$. Helium gas was the carrier at a flow rate of $1.0 \mathrm{~mL} \cdot \mathrm{min}^{-1}$ with primary pressure of $700 \mathrm{kPa}$. Tandem MS was equipped with a detector (GCMS-QP2010, Shimadzu) with ion source range (35 to $600 \mathrm{~m} \cdot \mathrm{z}^{-1}$ ) for identification of the wax components. The detection MS interface and ion source temperatures were 290 and $260{ }^{\circ} \mathrm{C}$, respectively, and a split ratio of 20 . Amounts of individual waxes are reported as peak areas per leaf fresh weight after adjusting to the internal docosane standard.

ONion THRIPS EVALUATIONS. In 2016 and 2017, seeds from the 14 accessions (Table 1) were planted in a greenhouse as described. At $\approx 105 \mathrm{~d}$ after sowing, plants were moved outside and covered with black nets for $2 \mathrm{~d}$. Fifteen plants per accession were then transplanted into three blocks at $5 \mathrm{~cm}$ distance between plants and a $10 \mathrm{~cm}$ separation between plots in a RCBD at the UW Horticulture Research Farm. Plots were not sprayed with pesticides and natural populations of onion thrips colonized plots from adjacent sources. Three evaluators visually classified the foliage type of each accession using the scale of $1=$ glossy, $3=$ semiglossy, and $5=$ waxy foliage (Fig. 1). Plants were scored when feeding damage by onion thrips was severe on waxy DH2107. Four evaluators independently scored damage on each replicated plot using a severity scale of 1 to 9 , where $1=$ no damage and $9=$ severe damage.

DAta ANALYSIS. Peak areas for each wax component were averaged from the two leaf samples from each plant, yielding six observations corresponding to the six plants per accession from the CF16 and GH17 plantings and two observations per 
block from the Arl17A and Arl17B plantings. Statistical analyses were performed in $\mathrm{R}$ studio ( $\mathrm{R}$ Foundation for Statistical Computing, Vienna, Austria). Accessions were considered as fixed and evaluations, accession-by-evaluation interaction, and blocks as random variables. Analysis of variance for fixed effects used the anova function and for the mixed model analyses the Lmer package with function lmer. Significant differences for wax composition among accessions were tested using the package emmeans and Tukey's honestly significant differences test at $P=0.05$. R package multcompView with function cld was used to extract and display pairwise comparisons of estimated marginal means using parameters adjust="tukey". The model used to estimate accession means in the CF16 and GH17 evaluations was $\mathrm{y}_{\mathrm{ijl}}=\mu+$ $\mathrm{g}_{\mathrm{i}}+\mathrm{t}_{\mathrm{j}}+\mathrm{g}_{\mathrm{tij}}+\varepsilon_{\mathrm{ijl}}$ where $\mu$ is the overall mean, $\mathrm{g}_{\mathrm{i}}$ is the fixed effect of the $i^{\text {th }}$ onion accession, $t_{j}$ is the random effect of the $j^{\text {th }}$ evaluation, $\mathrm{g}_{\mathrm{tij}}$ is the random effect of the $\mathrm{ij}^{\text {th }}$ accession by evaluation, and $\varepsilon_{\mathrm{ijk}}$ are residuals. For the Arl17A and Arl17B evaluations, the model was $\mathrm{y}_{\mathrm{ijkl}}=\mu+$ $\mathrm{g}_{\mathrm{i}}+\mathrm{t}_{\mathrm{j}}+\mathrm{gt}_{\mathrm{ij}}+\beta_{\mathrm{k}}+\varepsilon_{\mathrm{ijk} l}$ where $\gamma_{\mathrm{k}}$ is the random effect of the $\mathrm{k}^{\text {th }}$ block. The model used for thrips damage was $\mathrm{y}_{\mathrm{ijtl}}=\mu+\mathrm{g}_{\mathrm{i}}+\mathrm{e}_{\mathrm{j}}+\mathrm{b}_{\mathrm{t}}+\varepsilon_{\mathrm{ijtl}}$ where $\mu$ is the overall mean, $g_{\mathrm{i}}$ is the fixed effect of the $i^{\text {th }}$ onion accession, $e_{j}$ is the random effect of the $j^{\text {th }}$ evaluator, $b_{t}$ is the random effect of the $t^{\text {th }}$ block, and $\varepsilon_{\mathrm{ijtl}}$ are residuals. Evaluator by block interaction was not significant and therefore not included in the mixed model. Pearson's correlations between proportions of individual waxes using estimated accession means and mean estimates of thrips damage were calculated based on these models.

\section{Results}

Epicuticular wax Profiles. Eight waxes were detected on foliage of the onion accessions (Tables 2 and 3): 2-methyloctacosane (Met), H16, hexacosanol-1 (Hex), heptacosane (Hepc), heptadecane (Hepd), octaconasol-1 (Oct1), octadecane (Octd), and triacontanol-1 (Tri1), in agreement with Damon et al. (2014). H16 was the most prevalent wax on the foliage of all accessions except glossy B9885 (Tables 2 and 3) and ranged from $21 \%$ to $71 \%$ of the total epicuticular wax (Table 4). A visually assessed waxy phenotype was most obvious when H16 comprised more than two-thirds of total wax amounts, consistent with Gülz et al. (1992) who proposed that wax crystals build up on the leaf surface when one lipid class predominates. However in some cases waxy and semiglossy accessions had the same amounts of total wax on foliage (e.g., as waxy 288903 and semiglossy 546101 in Tables 2 and 3), and similar percentages of H16 to total wax (waxy 264648 and semiglossy 546201 in Table 4).

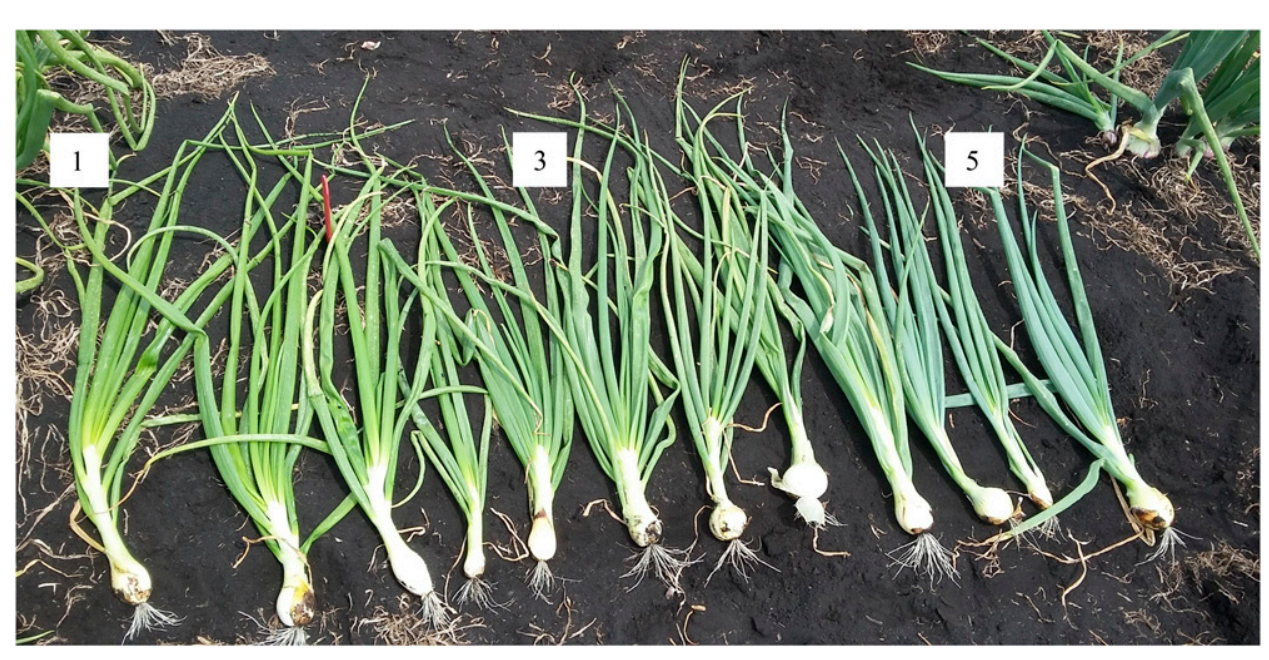

Fig. 1. Visually scored phenotypes of onion foliage from left to right: $1=$ glossy, $3=$ semiglossy, and $5=$ waxy.

Table 2. Mean peak areas adjusted to internal standard as measured by gas chromatography for eight epicuticular waxes, total wax amount and visually assessed foliar phenotypes of 14 onion accessions grown in completely randomized design in coldframe 2016 and greenhouse 2017. Accessions sorted from highest to lowest amount of hentriacontanone-16 (H16).

\begin{tabular}{|c|c|c|c|c|c|c|c|c|c|c|c|c|c|c|c|c|c|c|c|}
\hline \multirow[b]{2}{*}{ Accession } & \multirow[b]{2}{*}{ Phen $^{z}$} & \multicolumn{18}{|c|}{ Waxes $^{\mathrm{y}}$} \\
\hline & & $\overline{\mathrm{H} 16}$ & & Oct1 & & Tri1 & & Met & & Hex & & Octd & & Hepd & & Hepc & & Total & \\
\hline 546096 & WX & 3.48 & $\mathrm{a}$ & 0.49 & $\mathrm{a}$ & 0.19 & cde & 0.06 & $\mathrm{a}$ & 0.14 & $\mathrm{a}$ & 0.05 & $a b$ & 0.16 & $\mathrm{ab}$ & 0.18 & $\mathrm{a}$ & 4.75 & $\mathrm{a}$ \\
\hline $22452 \mathrm{AA}$ & WX & 2.39 & $\mathrm{~b}$ & 0.32 & $a b c$ & 0.14 & de & 0.14 & $\mathrm{a}$ & 0.02 & $\mathrm{a}$ & 0.07 & $\mathrm{a}$ & 0.22 & $\mathrm{a}$ & 0.23 & $\mathrm{a}$ & 3.53 & $a b$ \\
\hline DH2107 & WX & 2.27 & $\mathrm{~b}$ & 0.34 & $a b c$ & 0.20 & bcde & 0.04 & $\mathrm{a}$ & 0.09 & $\mathrm{a}$ & 0.02 & cde & 0.09 & cde & 0.11 & $\mathrm{a}$ & 3.16 & bc \\
\hline 546106 & WX & 2.00 & $\mathrm{bc}$ & 0.33 & $a b c$ & 0.17 & cde & 0.09 & $\mathrm{a}$ & 0.04 & $\mathrm{a}$ & 0.04 & bc & 0.10 & cde & 0.27 & $\mathrm{a}$ & 3.04 & bc \\
\hline 288903 & WX & 1.94 & bcd & 0.29 & $a b c$ & 0.14 & de & 0.05 & $\mathrm{a}$ & 0.04 & $\mathrm{a}$ & 0.05 & $a b$ & 0.11 & bcde & 0.10 & a & 2.72 & bcd \\
\hline 546201 & SG & 1.72 & bcd & 0.33 & $a b c$ & 0.38 & $\mathrm{a}$ & 0.02 & $\mathrm{a}$ & 0.00 & $\mathrm{a}$ & 0.00 & $\mathrm{e}$ & 0.06 & de & 0.02 & $\mathrm{a}$ & 2.53 & $\mathrm{~cd}$ \\
\hline 546192 & SG & 1.72 & bcde & 0.50 & $\mathrm{a}$ & 0.32 & $a b c$ & 0.04 & $\mathrm{a}$ & 0.00 & $\mathrm{a}$ & 0.02 & de & 0.09 & cde & 0.06 & $\mathrm{a}$ & 2.75 & $d$ \\
\hline 546101 & SG & 1.62 & bcde & 0.41 & $\mathrm{ab}$ & 0.33 & $a b$ & 0.15 & $\mathrm{a}$ & 0.10 & $\mathrm{a}$ & 0.03 & bcde & 0.13 & bcd & 0.40 & $\mathrm{a}$ & 3.17 & $\mathrm{bc}$ \\
\hline B5351C & SG & 1.23 & cde & 0.15 & $\mathrm{c}$ & 0.09 & $\mathrm{e}$ & 0.08 & $\mathrm{a}$ & 0.01 & $\mathrm{a}$ & 0.03 & bcde & 0.15 & $a b c$ & 0.18 & $\mathrm{a}$ & 1.92 & cde \\
\hline $264320-2$ & SG & 1.13 & de & 0.42 & $a b$ & 0.27 & abcd & 0.13 & $\mathrm{a}$ & 0.05 & $\mathrm{a}$ & 0.03 & bcde & 0.11 & bcde & 0.21 & $\mathrm{a}$ & 2.35 & \\
\hline $264320-1$ & SG & 0.75 & ef & 0.32 & $a b c$ & 0.18 & cde & 0.10 & $\mathrm{a}$ & 0.05 & $\mathrm{a}$ & 0.02 & de & 0.08 & de & 0.15 & $\mathrm{a}$ & 1.65 & de \\
\hline
\end{tabular}

${ }^{\mathrm{z}}$ Visually classified phenotypes of glossy (GL), semiglossy (SG), or waxy (WX) foliage.

${ }^{\mathrm{y}}$ Waxes are hentriacontanone-16 (H16), octaconasol-1 (Oct1), and triacontanol-1 (Tri1), 2-methyloctacosane (Met), hexacosanol-1 (Hex), octadecane (Octd), heptadecane (Hepd), and heptacosane (Hepc). Means followed by the same letter are not significantly different using Tukey's honestly significant differences test at $P=0.05$. 
Table 3. Mean peak areas adjusted to internal standard as measured by gas chromatography for eight epicuticular waxes, total wax amount and visual foliar phenotypes on the foliage of 13 onion accessions grown in a randomized complete block design at two locations on the UW Horticulture Research Farm in 2017. Accessions sorted from highest to lowest amount of hentriacontanone-16 (H16).

\begin{tabular}{|c|c|c|c|c|c|c|c|c|c|c|c|c|c|c|c|c|c|c|c|}
\hline \multirow[b]{2}{*}{ Accession } & \multirow[b]{2}{*}{ Phen $^{z}$} & \multicolumn{18}{|c|}{ Waxes $^{\mathrm{y}}$} \\
\hline & & $\overline{\mathrm{H} 16}$ & & Oct1 & & Tri1 & & Met & & Hex & & Octd & & Hepd & & Hepc & & Total & \\
\hline$\overline{546096}$ & WX & 2.24 & $\mathrm{a}$ & 0.67 & $a$ & 0.28 & $a b$ & 0.02 & $\mathrm{c}$ & 0.04 & $a b c$ & 0.06 & $a b c$ & 0.20 & $\mathrm{a}$ & 0.07 & $a b c$ & 3.58 & $\mathrm{a}$ \\
\hline 288903 & WX & 2.07 & $a b$ & 0.39 & bcd & 0.14 & cde & 0.03 & $\mathrm{bc}$ & 0.03 & abcd & 0.07 & $a b$ & 0.15 & $a b$ & 0.05 & $\mathrm{bc}$ & 2.93 & $a b$ \\
\hline $22452 \mathrm{AI}$ & WX & 1.85 & $a b$ & 0.35 & cde & 0.12 & de & 0.07 & $\mathrm{a}$ & 0.04 & $a b c$ & 0.07 & $\mathrm{a}$ & 0.19 & $\mathrm{a}$ & 0.08 & $a b$ & 2.77 & $a b$ \\
\hline 264648 & WX & 1.72 & $a b c$ & 0.47 & $\mathrm{bc}$ & 0.22 & abcd & 0.01 & $\mathrm{c}$ & 0.04 & abcd & 0.04 & bcd & 0.16 & $a b$ & 0.05 & $\mathrm{bc}$ & 2.71 & $a b$ \\
\hline 546106 & WX & 1.67 & $a b c$ & 0.47 & bc & 0.26 & $a b c$ & 0.02 & $\mathrm{c}$ & 0.03 & bcd & 0.04 & $\mathrm{~cd}$ & 0.09 & bcd & 0.06 & $a b c$ & 2.64 & $a b$ \\
\hline $2452 \mathrm{AA}$ & WX & 1.30 & bcd & 0.39 & bcd & 0.15 & bcde & 0.06 & $a b$ & 0.04 & $a b c$ & 0.09 & $\mathrm{a}$ & 0.17 & $a b$ & 0.07 & $a b c$ & 2.27 & $\operatorname{cde}$ \\
\hline 546101 & SG & 1.30 & bcd & 0.52 & $a b$ & 0.31 & $\mathrm{a}$ & 0.02 & $\mathrm{c}$ & 0.05 & $a b$ & 0.04 & $\mathrm{~cd}$ & 0.14 & $a b c$ & 0.07 & $a b c$ & 2.45 & $a b c$ \\
\hline 546192 & $\mathrm{SG}$ & 0.88 & cde & 0.23 & def & 0.11 & de & 0.03 & $\mathrm{bc}$ & 0.02 & $\mathrm{~cd}$ & 0.03 & def & 0.09 & bcd & 0.08 & $a b$ & 1.47 & cdef \\
\hline B5351C & SG & 0.70 & de & 0.17 & ef & 0.08 & $\mathrm{e}$ & 0.03 & $\mathrm{bc}$ & 0.01 & d & 0.03 & de & 0.15 & $a b c$ & 0.11 & $\mathrm{a}$ & 1.28 & def \\
\hline $264320-1$ & SG & 0.66 & de & 0.14 & $\mathrm{f}$ & 0.09 & $\mathrm{e}$ & 0.03 & $\mathrm{bc}$ & 0.03 & $\mathrm{~cd}$ & 0.01 & $\mathrm{f}$ & 0.08 & $\mathrm{~cd}$ & 0.08 & $a b$ & 1.12 & ef \\
\hline $9885 \mathrm{C}$ & GL & 0.08 & e & 0.33 & cde & 0.18 & bcde & 0.03 & $\mathrm{bc}$ & 0.04 & $a b c$ & 0.04 & $\mathrm{~cd}$ & 0.04 & d & 0.02 & $\mathrm{c}$ & 0.76 & $\mathrm{f}$ \\
\hline
\end{tabular}

${ }^{\mathrm{z}}$ Visually classified phenotypes of glossy (GL), semiglossy (SG), or waxy (WX) foliage.

${ }^{\mathrm{y}}$ Waxes are hentriacontanone-16 (H16), octaconasol-1 (Oct1), triacontanol-1 (Tri1), 2-methyloctacosane (Met), hexacosanol-1 (Hex), octadecane (Octd), heptadecane (Hepd), and heptacosane (Hepc). Means followed by the same letter are not significantly different using Tukey's honestly significant differences test at $P=0.05$.

Table 4. Visual assessed foliar phenotypes, mean feeding damage by onion thrips, and percentages of individual epicuticular waxes for onion accessions as measured by gas chromatography across evaluations. Accessions sorted from highest to lowest feeding damage.

\begin{tabular}{|c|c|c|c|c|c|c|c|c|c|c|c|c|}
\hline \multirow[b]{2}{*}{ Accession } & \multirow[b]{2}{*}{ Phen $^{z}$} & \multicolumn{3}{|c|}{ Feeding damage $(1-9 \text { scale })^{\mathrm{y}}$} & \multicolumn{8}{|c|}{ Composition of wax $(\%)^{x}$} \\
\hline & & Mean & SE & & H16 & Oct1 & Tril & Met & Hex & Octd & Hepd & Hepc \\
\hline $\mathrm{DH} 2107$ & WX & 7.6 & 0.40 & $\mathrm{a}$ & 71.5 & 10.7 & 6.3 & 1.3 & 3.0 & 0.6 & 3.0 & 3.6 \\
\hline 546106 & WX & 7.5 & 0.71 & $\mathrm{a}$ & 65.6 & 10.9 & 5.6 & 3.0 & 1.3 & 1.4 & 3.3 & 8.9 \\
\hline 288903 & WX & 7.2 & 0.40 & $\mathrm{a}$ & 71.3 & 10.6 & 5.0 & 1.8 & 1.6 & 1.7 & 4.0 & 4.0 \\
\hline 546096 & WX & 6.8 & 0.40 & $\mathrm{a}$ & 73.0 & 10.2 & 4.0 & 1.3 & 3.1 & 1.0 & 3.4 & 4.0 \\
\hline $22452 \mathrm{AA}$ & WX & 6.6 & 0.40 & $\mathrm{a}$ & 67.4 & 9.0 & 3.8 & 3.9 & 0.6 & 1.9 & 6.2 & 7.2 \\
\hline 546201 & SG & 4.2 & 0.40 & $\mathrm{bc}$ & 61.5 & 11.9 & 13.1 & 2.3 & 2.2 & 0.1 & 2.9 & 6.0 \\
\hline 546101 & SG & 3.5 & 0.40 & $\mathrm{~cd}$ & 50.1 & 12.6 & 10.2 & 5.1 & 3.4 & 1.0 & 4.2 & 13.4 \\
\hline 546192 & SG & 3.3 & 0.40 & $\mathrm{~cd}$ & 56.8 & 17.1 & 10.1 & 2.7 & 2.0 & 0.5 & 3.8 & 7.0 \\
\hline $9885 \mathrm{C}$ & GL & 3.2 & 0.40 & $\mathrm{~cd}$ & 24.1 & 32.5 & 14.1 & 6.7 & 1.7 & 3.7 & 5.3 & 11.9 \\
\hline $264320-2$ & SG & 2.8 & 0.40 & $\mathrm{~cd}$ & 47.5 & 17.9 & 11.2 & 5.7 & 2.3 & 1.2 & 4.7 & 9.4 \\
\hline B5351C & SG & 2.3 & 0.40 & $\mathrm{~cd}$ & 58.3 & 7.2 & 3.7 & 5.1 & 2.0 & 1.6 & 8.1 & 14.0 \\
\hline
\end{tabular}

${ }^{\mathrm{z}}$ Visually classified phenotypes of glossy (GL), semiglossy (SG), or waxy (WX) foliage (Table 1).

${ }^{\mathrm{y}}$ Scores for feeding damage by onion thrips were from four evaluators using scale from $1=$ no damage to $9=$ severe damage. Means followed by the same letter are not significantly different using Tukey's honest significant difference test at $P<0.05$.

${ }^{\mathrm{x}}$ Waxes are hentriacontanone-16 (H16), octaconasol-1 (Oct1), triacontanol-1 (Tri1), 2-methyloctacosane (Met), hexacosanol-1 (Hex), octadecane (Octd), heptadecane (Hepd), and heptacosane (Hepc).

$*$, ** Significant at $P<0.05$ or 0.01 , respectively.

Amounts of the fatty alcohol Oct1 ranged from $10 \%$ to $36 \%$ of the total wax load; glossy B9885 had the largest proportion of Oct1 at 36\%, and 264320-1 and 264320-2 had relatively large proportions at $\approx 18 \%$ each (Table 4 ). Amounts of the fatty alcohol Tri1 were lower than Oct1 and ranged from 5\% to $15 \%$ of the total wax load (Table 4). The proportion of the alkane Hepc was relatively high in accessions B5351, 264320-1, and 546101 (Table 4). The other waxes represented relatively minor components $(<10 \%)$ of the total wax profile (Tables $2-4)$. We detected an average of $20 \%$ less total wax on accessions grown in the Arl17A and Arl17B vs. CF16 and GH17 evaluations
(Tables 2 and 3), indicating that visual foliar phenotypes may be more distinct under field conditions due to lower amounts of total wax.

From analyses of the CF16 and GH17 evaluations, accession was highly significant $(P<0.001)$ for the three most prevalent waxes (H16, Oct1, and Tri1) and explained $41.1 \%, 14.7 \%$, and $6.9 \%$ of the variation, respectively. Evaluation (CF16 vs. GH17) was significantly different for H16 $(P=0.025)$ and Tri1 $(P<0.01)$; however, evaluation explained only $0.7 \%, 4.0 \%$, and $0.1 \%$ of the total variation for H16, Oct1, and Tri1, respectively. The accession-by-evaluation interaction was significant for $\mathrm{H} 16$ 
Table 5. Pearson correlation coefficients among amounts of hentricontanone-16 (H16), octacosanol-1 (Oct1), and triacontanol-1 (Tri1) on foliage of onion accessions grown in coldframe in 2016 (CF16), greenhouse in 2017 (GH17), and at two locations on the University of Wisconsin Horticulture Research Farm in 2017 (Arl17A and Arl17B). All correlations were significant at $P=0.05$

\begin{tabular}{|c|c|c|c|c|c|c|c|c|c|}
\hline & \multicolumn{3}{|c|}{ H16 } & \multicolumn{3}{|c|}{ Oct1 } & \multicolumn{3}{|c|}{ Tri1 } \\
\hline & $\overline{\mathrm{GH} 17}$ & Arl17A & $\overline{A r l 17 B}$ & $\overline{\mathrm{GH} 17}$ & Arl17A & $\overline{A r l 17 B}$ & $\overline{\mathrm{GH} 17}$ & Arl17A & $\overline{A r l 17 B}$ \\
\hline$\overline{\text { CF16 }}$ & 0.89 & 0.81 & 0.76 & 0.34 & 0.34 & 0.34 & 0.39 & 0.45 & 0.68 \\
\hline GH17 & & 0.79 & 0.73 & & 0.50 & 0.53 & & 0.55 & 0.46 \\
\hline Arl17A & & & 0.8 & & & 0.97 & & & 0.89 \\
\hline
\end{tabular}

confirmed that glossy and semiglossy phenotypes suffer significantly less feeding damage by onion thrips compared with waxy onion (Table 4), agreeing with previous researchers (Cramer et al., 2014; Damon et al., 2014; DiazMontano et al., 2010; Jones et al., 1935; Maughan and MacLeod, 1936) but disagreeing with $\mathrm{Njau}$ et al. (2017). Glossy and semiglossy $(P=0.009)$ and Tri1 $(P<0.011)$ and contributed more to the total variation at $6.8 \%, 7.4 \%$, and $10.6 \%$ for $\mathrm{H} 16$, Octl, and Tri1, respectively. For the Arl17A and Arl17B evaluations, accession was highly significant $(P<0.001)$ for H16, Oct1, and Tri1. Evaluation was significant for H16 and Tril (both $P<0.001$ ), accession-byevaluation interaction was significant for $\mathrm{H} 16$ and Tril (both $P<0.011$ ), and blocks were not significant for H16, Oct1, and Tri1. For H16, accessions explained the largest proportion of the variation at $33.9 \%$, followed evaluation at $21.4 \%$ and accession-by-evaluation at $4.7 \%$. For Oct 1 , the proportion of variance explained by accession was $57.5 \%$; the evaluation and accession-by-evaluation interaction were essentially zero. For Tri1, accession contributed the largest proportion at $28.7 \%$, followed by the evaluation at $15.7 \%$ and accession-by-evaluation at $6.8 \%$ of the total phenotypic variance.

ONION THRIPS DAMAGE. In the 2016 field evaluation, visually scored feeding damage by onion thrips was significantly different $(P<0.001)$ among accessions, and the glossy and semiglossy selections showed significantly lower damage compared with the waxy onion (Table 4). Feeding damage was significantly $(P<0.05)$ correlated with total amounts of $\mathrm{H} 16$ at 0.69 and 0.68 from evaluations $\mathrm{CF} 16 / \mathrm{GH} 17$ and Arl17A/Arl17B, respectively. Amounts of Oct1 and Tril were not significantly correlated with feeding damage at the 0.05 level in CF16/GH17, and only Oct1 for plants grown in the Arl17A/Arl17B evaluations was significantly $(P<0.05)$ correlated with less feeding damage by onion thrips. The percentages of H16, Met, and Tri1 to total wax amounts were significantly correlated with onion thrips damage at 0.73 , -0.63 , and -0.65 , respectively (Table 4 ), indicating that lower amounts of H16 and Met and higher amounts of the other waxes were correlated with less feeding damage. No significant differences were observed for damage scores in the 2017 evaluation due to low numbers of onion thrips.

Phenotypic Correlations and VARIANCe COMPONents. Pearson correlations among evaluations (CF16, GH17, Arl17A, and Arl17B) were all significant $(P<0.05)$ for the three main waxes and were consistent with those reported in a segregating family by Damon and Havey (2014). Correlations for amounts of H16 ranged from 0.89 to 0.73 (Table 5). Correlations for amounts of Oct1 ranged from 0.97 to 0.34 and for Tri1 between 0.89 and 0.39 (Table 5). The lower correlations for Oct1 and Tri1 across evaluations could be due to greater environmental effect on amounts of these fatty alcohols, or greater variation in their measurements because of lower amounts.

\section{Discussion}

We measured types and amounts of epicuticular waxes on the foliage of glossy, semiglossy, and waxy onions and accessions had lower amounts of H16 relative to the other wax components; however, these phenotypes may have larger amounts of other waxes such as fatty alcohols or alkanes (Tables 2 and 3). Amounts of total epicuticular wax varied among accessions within the same visual phenotypes, and semiglossy accessions were identified with the same total epicuticular wax as waxy plants (Tables 2 and 3). Selections from PIs 546192 and 546201 had smaller proportions of H16 on foliage and increased amounts of other waxes such as the alkane Hepc and fatty alcohols Oct1 and Tri1 (Table 4). The selection from PI 546192 possessed as much total wax as some waxy phenotypes and showed lower feeding damage by onion thrips, agreeing with observations by Cramer et al. (2014). In subsequent research, Cramer et al. (2017) concluded that lighter leaf color and/or a reduced amount of epicuticular wax did not always result in the fewest number of onion thrips per plant; however, Cramer et al. (2017) relied on visual classification of foliage phenotypes and did not quantitatively measure amounts and types of leaf waxes. Our research demonstrates that the composition of epicuticular waxes is important for reduced damage by onion thrips. Selection of onion for lower amounts of H16 and higher amounts of other waxes, such as alkanes and fatty alcohols, should produce phenotypes that suffer less feeding damage by onion thrips. These onions would still be damaged by onion thrips; however, they may require fewer insecticide applications for adequate control (Nault and Huseth, 2016) and potentially delay or avoid the development of insecticide resistance often associated with frequent spraying.

\section{Literature Cited}

Boateng, C.O., H.F. Schwartz, M.J. Havey, and K. Otto. 2014. Evaluation of onion germplasm for resistance to iris yellow spot (Iris yellow spot virus) and onion thrips, Thrips tabaci. Southwest. Entomol. 39:237-260.

Cramer, C.S., N. Singh, N. Kamal, and H.R. Pappu. 2014. Screening onion plant introduction accessions for tolerance to onion thrips and iris yellow spot. HortScience 49:1253-1261.

Cramer, C.S., N. Kamal, and N. Singh. 2017. Evaluating iris yellow spot disease incidence and severity in onion germplasm of varying leaf characteristics. HortScience 52:527-532.

Damon, S.J. and M.J. Havey. 2014. Quantitative trait loci controlling amounts and types of epicuticular waxes in onion. J. Amer. Soc. Hort. Sci. 139:597-602.

Damon, S.J., R.L. Groves, and M.J. Havey. 2014. Variation for epicuticular waxes on onion foliage and impacts on numbers of onion thrips. J. Amer. Soc. Hort. Sci. 139:495-501.

Diaz-Montano, J., M. Fuchs, B.A. Nault, and A.M. Shelton. 2010. Evaluation of onion cultivars for resistance to onion thrips (Thysanoptera: Thripidae) and Iris Yellow Spot Virus. J. Econ. Entomol. 103:925-937.

Elmore, J.C. 1949. Thrips injury to onions grown for seed. J. Econ. Entomol. 42:756-760. 
Fournier, F., G. Boivin, and R.K. Stewart. 1995. Effect of Thrips tabaci (Thysanoptera: Thripidae) on yellow onion yields and economic thresholds for its management. J. Econ. Entomol. 88:1401-1407.

Gülz, P.G., E. Müller, and K. Schmitz. 1992. Chemical composition and surface structures of epicuticular leaf waxes of Ginkgo bilboa, Magnolia grandiflora and Liriodendron tulipifera. Zeitschrift fur Naturforschung 47:516-526.

Herron, G.A., T.M. James, and J.M. Rophail. 2008. Australian populations of onion thrips, Thrips tabaci Lindeman (Thysanoptera: Thripidae), are resistant to some insecticides used for their control. Austral. J. Entomol. 47:361-364.

Hyde, P.T., E.D. Earle, and M.A. Mutschler. 2012. Doubled haploid onion (Allium cepa L.) lines and their impact on hybrid performance. HortScience 47:1690-1695.

Jones, H.A., A.E. Clarke, and F.J. Stevenson. 1944. Studies in the genetics of the onion (Allium cepa L). Proc. Amer. Soc. Hort. Sci. 44:479-484.

Jones, H.A., S.F. Bailey, and S.L. Emsweller. 1934. Thrips resistance in onion. Hilgardia 8:215-232.

Jones, H.A., S.F. Bailey, and S.L. Emsweller. 1935. Field studies of Thrips tabaci Lind. with special reference to resistance in onions. J. Econ. Entomol. 28:678-680.

Kendall, D.M. and J.L. Capinera. 1987. Susceptibility of onion growth stages to onion thrips (Thysanoptera: Thripidae). Damage and mechanical defoliation. Environ. Entomol. 16:859-863.
Maughan, F.B. and G.F. MacLeod. 1936. Further studies of onion varieties and onion thrips. J. Econ. Entomol. 29:335-339.

Molenaar, N.D. 1984. Genetics, thrips (Thrips tabaci L.) resistance and epicuticular wax characteristics of nonglossy and glossy onions (Allium cepa L.). PhD Diss., Univ. WisconsinMadison.

Nault, B.A. and A.S. Huseth. 2016. Evaluating an action thresholdbased insecticide program on onion cultivars varying in resistance to onion thrips (Thysanoptera: Thripidae). J. Econ. Entomol. 109:1772-1778.

Njau, G.M., A.M.S. Nyomora, F.F. Dinssa, J.C. Chang, P. Malini, S. Subramanian, and R. Srinivasan. 2017. Evaluation of onion (Allium сера) germplasm entries for resistance to onion thrips, Thrips tabaci (Lindeman) in Tanzania. Intl. J. Trop. Insect Sci. 37:98-113.

Parrella, M.P. and T. Lewis. 1997. Integrated pest management (IPM) in field crops. CAB Intl., New York, NY.

Rhee, Y., A. Hlousek-Radojcic, P. Ponsamuel, D. Liu, and P. Beittenmiller. 1998. Epicuticular wax accumulation and fatty acid elongation activities are induced during leaf development of leeks. Plant Physiol. 116:901-911.

Shelton, A.M., B.A. Nault, J. Plate, and J.Z. Zhao. 2003. Regional and temporal variation in susceptibility to $\lambda$-Cyhalothrin in onion thrips, Thrips tabaci (Thysanoptera: Thripidae), in onion fields in New York. J. Econ. Entomol. 96:1843-1848. 